\title{
Um olhar sobre o abrigamento: a importância dos vínculos em contexto de abrigo
}

\author{
A importância dos vínculos em abrigo
}

\author{
Célia Vectore \\ Cíntia Carvalho
}

\begin{abstract}
Resumo
Trata-se de um estudo objetivando compreender o universo da criança institucionalizada em abrigo. Para tanto, foram realizadas entrevistas semi-estruturadas com a equipe técnica da instituição, representadas pelo gestor, assistente social, secretário e com cinco profissionais, denominadas mães sociais, responsáveis pelos cuidados às crianças nas casas lares, além de duas funcionárias que assumem na ausência das mães sociais (mães folguistas). Os dados obtidos por meio das entrevistas permitiram a identificação de aspectos, como: concepções de infância da equipe, concepções acerca da família de origem e a formação de vínculos em contexto institucional, os quais mostram uma diversidade de pontos de vista e, conseqüentemente, de ações diferenciadas dos profissionais no trato junto à criança. Sugere-se a necessidade de novos estudos, haja vista a importância que assume a questão dos vínculos em uma institucionalização de qualidade para crianças em situação de risco.
\end{abstract}

Palavras-chave: Crianças, Abrigo, Vínculos.

\section{A glance at sheltering: the importance of the ties in a shelter context}

\begin{abstract}
This study aims at understanding the universe of the child institutionalized in a shelter. To achieve this goal it was performed semi-structered interviews with the technical crew of the institution, represented by the manager, the social agent, the secretary and five professionals (know as social mothers) who are responsible for taking care of the children in the shelters, as well as with two employees (know as time off mothers) who take place in the absence of the social mother. The data colected from the interviews allowed the identification of aspects such as: the childhood conception of the crew; conceptions about the family of origin and the establishing of linkings in institutional context. These results show a diversity of viewpoints and, consequently, different actions in dealing with the child. This is a worrying feature considering the age of the children dealt with in the research.
\end{abstract}

Keywords: Children, Shelter, Ties.

\section{Una visión sobre el asilamiento: la importancia de los vínculos en el contexto de asilo}

\begin{abstract}
Resumen
Se trata de un estudio con el objetivo de entender el universo del niño institucionalizado en asilo. Para eso fueron realizadas entrevistas semi-estructuradas con el equipo técnico de la institución, representados por el gestor, asistente social, secretario y cinco profesionales denominadas madres sociales, responsables por los cuidados a los niños en las casas hogares, además de dos funcionarias que asumen en la ausencia de las madres sociales (madres en descanso). Los datos obtenidos por medio de las entrevistas permitieron la identificación de aspectos como: concepciones de infancia del equipo; concepciones sobre la familia de origen y la formación de vínculos en el contexto institucional, los cuales muestran una diversidad de puntos de vista y, por consecuencia, de acciones diferenciadas de los profesionales en el trato junto a los niños. Se sugieren nuevos estudios, teniendo en cuenta la importancia que asume la cuestión de los vínculos en una institucionalización de calidad para niños en situación de riesgo.

Palabras clave: Niños, Asilo, Vínculos
\end{abstract}




\section{Introdução}

A realidade da infância em situação de risco e vulnerabilidade é ainda, nos dias de hoje, em escala planetária, um desafio a ser enfrentado pela sociedade. A negligência, os maus-tratos, a exploração do trabalho infantil, a prostituição de crianças, o abandono delineiam um sombrio quadro, no qual uma parcela considerável da população mundial se insere.

Dados do Fundo das Nações Unidas para a Infância (2008) mostram que o "Brasil possui a maior população infantil de até 6 anos das Américas", o que representa $11 \%$ de toda a população brasileira. Contudo, a "grande maioria das crianças na primeira infância no Brasil se encontra em situação de pobreza".

Evidentemente atribuir simplesmente à pobreza a responsabilidade pela perversa realidade enfrentada por um grande número de crianças e por suas famílias trata-se de uma análise simplista, embora Panúncio (2004) aponte que, historicamente, as condições de crianças brasileiras em situação de risco são resultados de um desenvolvimento nacional negligente, do ponto de vista social, o qual envolve vários tipos de violência sofrida pela criança, seja ela física psicológica, permeada de negligências e violência sexual (Maia \& Williams, 2005).

Marcílio (1997) menciona que, desde o período colonial, existe uma negligência do poder público ao acolhimento de crianças abandonadas, relata a falta de entidades especiais de proteção e acolhimento às crianças, as quais, muitas vezes, eram abandonadas e deixadas à mercê da própria sorte. Nesse período, o acolhimento se devia ou por questão de caridade ou por uma espécie de investimento futuro, em que a criança seria um empregado, sem grandes custos. Em 1726, foi trazido para o Brasil pelos portugueses, um modelo de assistência religiosa, de origem italiana, conhecido como "Roda dos expostos" ou "Roda dos enjeitados", que serviu como modelo por 224 anos, que mesclava a caridade e a filantropia e foi uma das principais instituições que teve como intuito à proteção da infância abandonada no país, indo desde o período colonial, atravessando a época do Império e ainda conseguindo sustentação durante parte do período da República, sendo extinta apenas no século XX, em 1950.

Com o advento da República novos questionamentos sobre a infância deram origem a uma perspectiva mais humanista, no modo de se perceber a criança e adolescência abandonada no Brasil, contudo, apenas a partir da década de 70 , do século passado houve um maior enfrentamento e posicionamento quanto às questões referentes à cultura da infância (Freitas, 1997; Passeti, 1996), possibilitando a organização de diversas associações, que culminou com o Estatuto da Criança e do Adolescente (ECA) no Brasil, aprovado em Julho de 1990, o qual funciona como Lei Federal constituída pelo $n^{\circ} 8069$, que resguarda os direitos fundamentais da criança e do adolescente, bem como as penalidades para os que descumprirem suas cláusulas.

Em seu capítulo III, o ECA afirma que, toda criança ou adolescente tem direito a ser criado e educado no seio da sua família, e excepcionalmente, em família substituta, assegurada à convivência familiar e comunitária... Nesse sentido, é que a instituição abrigo se constitui com função de zelar, de proteger a criança e o adolescente por tempo determinado ou indeterminado, reivindicando mediante iniciativas judiciais a volta às famílias de origem ou a destituição de pátrio poder, que culminará em processos de adoção.

A institucionalização da criança em um abrigo é multifatorial, de acordo com o Levantamento Nacional de Abrigos para Crianças e Adolescentes da Rede de Serviço de Ação Continuada, realizado pelo Instituto de Pesquisa Econômica Aplicada - IPEA (2003), sendo os principais motivos, as condições de pobreza, o que descaracteriza o abrigo enquanto lugar temporário: a violência doméstica; o uso de entorpecentes e álcool por pais ou responsáveis; crianças moradoras de rua; crianças órfãs; cárcere dos pais ou responsáveis e abuso sexual praticado por familiares. A pobreza se constitui como o principal motivo de institucionalização; das cerca de vinte mil crianças e adolescentes abrigados, $78 \%$ destes têm o abrigo como único lugar de moradia. Esses dados ainda são precários tendo em vista que, o referido órgão fez uma avaliação dos abrigos públicos, o que não permite conhecer o funcionamento dos abrigos que funcionam em regime privado no país.

O reconhecimento da pobreza das famílias como fator determinante de abrigamento infantil atrelado aos dados contidos no relatório do Fundo das Nações Unidas para a Infância, Situação Mundial da Infância 2008 - Caderno Brasil, evidenciam que no país cerca de "11,5 milhões de crianças ou $56 \%$ das crianças brasileiras de até 6 anos de idade vivem em famílias cuja renda mensal está abaixo de 1/2 salário mínimo per capita por mês" (UNICEF, 2008, p. 8), o que parece indicar uma tendência contínua para futuras institucionalizações.

Vicente (1999) afirma que, a criança submetida à proteção do abrigo tem por algum tempo a história pessoal "suspensa", fato que leva Dorian (2003, p.73) a apontar que "não se pode eliminar uma história familiar sem que se viva muita dor, angústia e medo do presente e do futuro". Azôr (2005) acrescenta que há barreiras, muitas vezes impostas pela própria instituição, no sentido de impossibilitar aberturas de espaços para que dores, tristezas e violências sejam mais bem elaboradas, acabando por desconsiderar a subjetividade dos abrigados.

A criança que se encontra abrigada, além de enfrentar dificuldades oriundas de relações familiares difíceis, muitas vezes, ao adentrar o abrigo, onde sua estadia geralmente não é transitória, se depara com longos processos judiciais, perpetuando a situação de institucionalização, haja vista que cada dia passado na instituição pode dificultar o processo de adoção, por ultrapassarem o estágio de vida, geralmente preferido pelas famílias brasileiras, que é até os dois anos de idade.

Nesse sentido, Silva (2004, p. 95) afirma: "a convivência institucional possui características, específicas, em princípio, inultrapassáveis, como por exemplo, ser quase sempre mais alargada do que a familiar; decorrer entre crianças e jovens que sofreram adversidades, (...); ser mais fechada em relação ao mundo exterior do que aquela que, em geral, as famílias proporcionam; impor rotinas mais rígidas do que as que têm lugar numa casa familiar; oferecer menos oportunidades para adquirir ou praticar novas aptidões, bem como para reforçar ou elogiar". Para tanto, o contexto 
do abrigo deve ser cuidadosamente organizado, a fim de possibilitar o desenvolvimento adequado da criança e, para tanto se constituir como espaço de promoção de vínculos seguros. Dorian (2003) sugere a pertinência de se proporcionar aos abrigados, ambientes mais positivos, com maior segurança e estabilidade e promotores de resiliência, o que significa propiciar um local onde haja fatores de proteção para o desenvolvimento humano.

A resiliência pode ser definida como "a capacidade do ser humano responder de forma positiva às situações adversas que enfrenta, mesmo quando estas comportam risco potencial para sua saúde e/ou seu desenvolvimento" (Silva \& Lacharité, 2003, p.1); a resiliência pode ser construída, a partir das interações que o sujeito tem com a família ou ambiente em que vive. Oposto à resiliência se encontra o fator descrito como vulnerabilidade, que é entendido como uma predisposição individual que potencializa os efeitos de um estressor, resultando conseqüências negativas para 0 desenvolvimento psicológico do indivíduo (Cecconello \& Koller, 2000).

A despeito da grande multiplicidade de varáveis que envolvem o abrigamento infantil, Azôr e Vectore (2008), acreditam que estudos cuidadosos devam ser continuamente empreendidos, de modo a possibilitar uma melhor compreensão do fenômeno em toda a sua extensão e sutilezas e assim, contribuir para um atendimento de qualidade no âmbito institucional.

Desse modo, é urgente pensar em maneiras passíveis de promover um abrigamento de qualidade e promotor efetivo do desenvolvimento das crianças ali institucionalizadas. Esse estudo teve o objetivo de compreender a realidade de crianças abrigadas em uma instituição não governamental, localizada em uma cidade do interior de Minas Gerais, por meio do conhecimento das concepções das pessoas que, efetivamente, cuidam da criança em situação de risco, acerca do processo de institucionalização.

\section{Método}

\section{Participantes}

O trabalho foi realizado numa instituição abrigo, localizada em uma cidade do interior do Estado de Minas Gerais. Contou com a participação de seis educadoras, do gestor da instituição, da assistente social e do secretário.

\section{Instrumentos}

Os instrumentos utilizados no estudo foram: observação da rotina institucional, entrevistas semiestruturadas com o gestor, com a assistente social, com o secretário, com as mães sociais ${ }^{1}$ e com as mães folguistas ${ }^{2}$.

\section{Procedimentos}

Após as assinaturas dos termos de consentimento pelo juiz da Vara da Infância e Juventude e pelo gestor da instituição, teve início a coleta dos dados, a qual foi realizada aos sábados, devido à disponibilidade das

\footnotetext{
${ }^{1}$ Entende-se por mãe social, aquela contratada para morar no abrigo e cuidar de determinado grupo de crianças.

${ }^{2}$ Entende-se por mãe folguista, aquela que cobre as faltas e as folgas das mães sociais.
}

pessoas envolvidas e teve a duração de cerca de dez meses. Esclarece-se que o adentrar em uma instituição abrigo demanda uma espera significativa, representada pelo tempo de acesso ao juiz, permissão judicial para a execução do estudo, permissão do gestor da instituição pesquisada, procedimentos exigidos pelo Comitê de Ética da Universidade Federal de Uberlândia, entre outros. Foram realizadas duas entrevistas semi-estruturadas com o gestor da instituição, uma com a assistente social, uma com cada mãe social, num total de quatro e uma com cada mãe folguista, num total de duas e finalmente, uma com o secretário, perfazendo 502 minutos gravados em áudio, resultando um total de oito horas e vinte e dois minutos. Foi solicitada a entrevista com a coordenadora da instituição, contudo, todas as tentativas de entrevistá-la foram frustradas. Após a realização, as entrevistas foram transcritas, de modo a permitir o estabelecimento de algumas categorias de análise, como: concepção de criança e do seu desenvolvimento e aprendizagem; concepção das famílias das crianças abrigadas; os vínculos em contexto de abrigo. Ao final da pesquisa foi possível o acesso às histórias de vida das crianças participantes, via autorização judicial, condicionada à manutenção de sigilo absoluto às identidades dos envolvidos, por se tratar de segredo de justiça, o que permitiu um melhor conhecimento dos fatores determinantes do abrigamento. A coleta dos dados foi realizada no Fórum, junto a representantes do comissariado da Infância e Juventude.

\section{Resultados}

Os resultados obtidos por meio de entrevistas semiestruturadas com a equipe da instituição, com o levantamento dos dados nos prontuários das crianças serão apresentados em tópicos. A fim de contextualizar a instituição optou-se por uma breve descrição do local e, a seguir serão mencionados os principais achados de todas as atividades empreendidas no estudo.

Trata-se de uma instituição filantrópica, mantida por doações e subvenções da prefeitura. O local tem cerca de $9.500 \mathrm{~m}^{2}$, onde existem 6 casas, dentre as quais, a casa 1 funciona como secretaria e as casas 2, 3, 4 e 5 funcionam no sistema de casas-lares, a casa 6 serve de moradia ao gerente administrativo. Há uma extensa área verde com campo de futebol, horticultura, parque para as crianças e bancos de cimento junto ao parque. As casas-lares são arejadas, mobiliadas, possuem eletrodomésticos, brinquedos, e ressalta-se a existência de dispensa repleta de mantimentos, advindos de doações. Cada casa pode receber de dez a onze crianças. São cerca de 40 crianças atualmente abrigadas na instituição, com idade limite para admissão de sete anos, a não ser em caso de grupo de irmãos, cuja idade não é determinante, por priorizar a manutenção dos vínculos familiares. A institucionalização permanece até que seja possível o retorno para família ou forem adotados. Não ocorrendo nenhuma das opções, as crianças ficam no abrigo até completarem maioridade ou completarem seus estudos. A instituição mantém uma equipe de profissionais que consiste em um gestor, assistente social, secretário, professor de reforço, seis mães, sendo duas, mães folguistas, uma secretária e auxiliar de serviços gerais. Os projetos realizados dentro da instituição, geralmente são advindos de estágios das 
universidades e voluntários que oferecem algum tipo de assistência médica, odontológica, na área da informática e horticultura, contando também com professor de violino.

O trabalho foi iniciado por uma observação da rotina institucional, por um período de vinte horas. Desse modo, foi possível constatar que os horários são delimitados e todas as atividades ocorrem em períodos específicos; apenas o horário do parque é escolhido pela mãe social. Para melhor compreensão os achados das entrevistas serão apresentados nos blocos abaixo descritos, representados por categorias, como: concepção de criança e do seu desenvolvimento e aprendizagem; concepção das famílias das crianças abrigadas; os vínculos em contexto de abrigo.

- Gestor: um primeiro dado que chama a atenção é o modo como o gestor se refere às crianças ali abrigadas, diz que sempre gostou de trabalhar com elas "por ser matéria bruta a ser trabalhada" e "Nós iremos fazer uma experiência com o material humano pior possível... nosso material serão (sic) os meus, que considero maus alunos e os da noite que são péssimos também". Para ele, as principais dificuldades enfrentadas são a carência afetiva, os problemas de aprendizagem, os problemas de comportamento e, principalmente a manifestação de uma sexualidade adultificada nas crianças. Demonstra ter poucas expectativas com relação ao futuro dos abrigados que apresentam problemas, como os de aprendizagem, afirmando que "Infelizmente, não são todas as pessoas que têm condições de cursar um curso superior. Então tem que preparar pra ser um profissional capaz dentro da sua limitação". Assim, sua concepção de aprendizagem parece ser uma característica inerente, que se tem ou não, apresentando-se como algo estático, irreversível, insuperável. Com relação aos vínculos das crianças e suas famílias de origem, afirma que, o motivo das crianças estarem no abrigo, se deve, principalmente, aos maus tratos sofridos e menciona oferecer ajuda às mães que "têm uma raiz de bondade na história", contribuindo com o pagamento da moradia, água, luz etc, para que possam recuperar a guarda de seus filhos. Para tanto, devem parar de fumar, de beber e de se prostituir. A contratação das mães sociais segue os seguintes critérios: "ter mais de 40 anos, sem dependentes, sem marido, sem filhos pequenos, sem mãezinha velha pra cuidar, sem filhas mulheres, porque a mãe de mulher se apega muito a função de avó" e a demissão ocorre quando observa falta de amor, de disciplina interna ou ordem na casa, mas o que diz ser intolerável é o fato da mãe "bater" na criança: "Se eu souber que uma mãe bateu, tá demitida! Mas nem por isso ela pode ser banana; ela tem que se impor! Coitada! Ela tem que se impor mas não pode bater!" Acrescenta que, o vínculo entre crianças e mães sociais é um fator importante, ressaltando que deve ser o mais perto possível de uma verdadeira mãe. Vale apontar, contudo que, há uma grande rotatividade de mães sociais, devido ao baixo salário pago para o exercício da função. Outro dado interessante trazido pelo gestor refere-se ao modo como são rompidos os vínculos da criança que sai da instituição, normalmente devido à adoção, por famílias estrangeiras. Para ele, deveria ser dada maior atenção àquela que permanece no abrigo, conforme explica

... "A Larissa ficou excitada falando para todos que iria embora. $E$ as outras que não vão embora? E quando a Larissa recebeu um álbum de fotografia da casa onde ela ia morar? Mas, as outras que não foram, perguntam: - "Por que eu não fui?"(sic) "Por que só a Larissa?"

- Assistente social: um aspecto digno de nota referese à divergência entre os dados acerca do histórico das crianças por ela relatado e, os obtidos junto aos arquivos existentes no Fórum, demonstrando um conhecimento parcial dos motivos da institucionalização das crianças, embora no desempenho de suas funções, faça visitas aos locais de moradia das famílias, conforme pode ser observado na fala a seguir, quando relata ter "desistido" da mãe de Carina e Leonardo (crianças participantes da pesquisa),

... Não é higiene. É desordem das pessoas, falta discernimento, falta vontade, falta uma garra de trabalhar. A Júlia, nós arrumamos emprego para ela vir aqui, ela não vem, então arrume a casa, nós pagamos a diária..., não vem, então são pessoas que se acomodaram porque ganham muito, ganham cesta básica, ganha auxilio de outras entidades (itálico nosso).

Em relação ao modo de adoção, acredita ser inadequado, principalmente quando a adoção é estrangeira, considerando que as crianças são levadas para o exterior, após um contato de 15 a 30 dias, conforme previsto no Art.46, sessão 1 do Estatuto da Criança e do Adolescente. Acredita também não ser adequado que a criança, após ser adotada, mantenha vínculos com as pessoas da instituição, mas ressalta que isso também depende muito da família. Finalmente, relata que as dificuldades de seu trabalho são muitas, pois cada "cada criança é uma criança", conforme explica:

...Cada um reage de uma maneira, cada um com suas revoltas, com seu temperamento, com a sua história, com seus traumas, tem criança que a mãe tem autorização para vir visitá-la e ela não está vindo e essa criança tem um distúrbio emocional muito sério, ela chora muito quando a mãe não vem, berra. (...) Berra muito ali no portão, grita mesmo, é berrar "mãe você não veio!" "AAAAHH!" (...) Então cada um reage de uma maneira, são muitas tristezas, são muitos sofrimentos, são muitas perdas, o abandono, "Quem é minha mãe?" "Quem é meu pai?" "Por que eu estou aqui?" "O que eu estou fazendo aqui?" (itálico nosso)

- Secretário: reside na instituição e as suas funções se distribuem entre buscar remédios, levar crianças ao médico, receber doações, visitas etc, além de intervir no trato com as crianças, que segundo 
ele, era solicitado "quando a situação estava meio fora de controle". Sobre a sexualidade adultificada das crianças, aponta:

... Da maneira que eles cometem esses atos eles já começam a ficar pessoas erradas (itálico nosso) eles ficam (...) crianças até um pouco fora do normal (itálico nosso)... o que podermos estar fazendo é que através da bíblia, porque nós somos pessoas evangélicas (sic), então nós cremos muito no poder da palavra de Deus e eu estou sempre ensinando para ajudar na libertação...

O secretário ainda menciona outras situações freqüentes e que podem contribuir para a compreensão do processo desenvolvimento das crianças abrigadas, como por exemplo, a grande freqüência de casos de crianças mais velhas (de até 13 anos) que ainda urinam na cama e o grande contingente de crianças com dificuldades escolares (cita uma criança de 11 anos que ainda não sabe ler).

- Mães sociais e mães folguistas: trata-se de mulheres com idade média de 52 anos, sendo quatro solteiras e duas viúvas. A escolaridade varia entre magistério e ensino fundamental incompleto. O tempo de trabalho no abrigo situase entre seis e quatro anos (duas educadoras), variando de 16 meses a um mês para as demais. Durante os relatos foi possível observar que, as mães sociais e folguistas parecem gostar do que fazem, assumindo responsabilidades de uma mãe nos cuidados materiais e afetivos, conforme se depreende na fala, a seguir:

... Eu não tinha nenhuma formação (...) para cuidar delas, mas eu pensei amor eu tinha bastante para dar (Itálico nosso) e com isso faz quatro anos que estou aqui!

Entre as dificuldades apontadas no trabalho mencionam a rebeldia das crianças, principalmente, as mais velhas, que as agridem verbalmente ou com gestos. Além disso, enfatizam que mudanças abruptas, como a ocorrida no abrigo, para a criação da sede dos bebês, levando a separação de crianças para outras casas, provocou sofrimento, devido às rupturas de vínculos já estabelecidos com as crianças, conforme descrição de uma delas.

No dia foi um fracasso, o primeiro dia, as gritarias, as brigas, as resistências, não queriam sair da casa e eu com aquele trauma... Parecia que eu estava abandonando um filho, deixando ali em outra casa, deixando para lá que eu não te quero mais... 'Mãe Ana, não me deixe aqui não!' A Jeisa passou mal... Eu quero ficar na minha casa.

Tal sofrimento também é manifestado no momento da adoção, de acordo com os relatos Eu nem gosto de entrar nesse detalhe, ai (sic) porque eu já acho pesado para o meu coração!

O Túlio, ele ficou comigo mais de três anos, ele veio de outro abrigo, ficou comigo esse tempo todo e está com dois meses que foi para Itália... Isso que precisa ser trabalhado, para evitar um pouco de sofrimento porque ele estava se sentindo inseguro.

Outro aspecto doloroso evolvendo a adoção, de acordo com uma das mães, é a ruptura dos vínculos entre os pares, como o caso ocorrido de duas meninas que entraram juntas no abrigo e que eram como irmãs e apenas uma delas foi adotada

...A outra que ficou entrou em depressão, começou a dar trabalho, a criança preocupou tanto com a outra, que não comia, não dormia, ela falava assim: 'Tia, será que a Márcia está bem? Eu falei: 'Olha Lúcia, eu vou ligar para a tia e vou pedir para trazer a Márcia aqui para passear, para você ver, eu acredito que ela esteja bem', então eu liguei para ela e ela veio aqui, trouxe ela e ela (sic) mesmo falou para mim: 'Olha Vera, você não precisa ligar mais, porque eu não vou vir mais aqui com ela ... Porque se não, eles não se desligam daqui, não esquecem daqui'.

As mães ainda mencionaram que, muitas crianças, desejam retornar para sua família de origem e para a maioria das entrevistadas, as mães se sentem acomodadas com suas crianças abrigadas e há aquelas que acham que seus filhos estão hospedados num "hotelzinho de luxo" (sic), por outro lado, reconhecem que há casos de mães que fazem de tudo para terem seus filhos de volta, outras, contudo, como uma mãe que está com cinco filhos abrigados, demonstram desinteresse pelas crianças, finalizando: ...acho monstruoso, essas mães que perdem seus filhos, como se perdessem uma banana na feira(sic)!

As mães também apontam que 0 desenvolvimento e aprendizagem das crianças abrigadas são continuamente marcados por situações, como: enurese noturna, dificuldades escolares, sexualidade, dificuldades de comportamento em casa, ou na escola. Uma das educadoras relatou ter casos, em sua casa, de "meninos que transam com outros meninos" e justifica tais atos por ter presenciado cenas de sexo entre seus genitores: O pai e a mãe teriam que ter uma vida particular muito zelada, porque, olha o que fez com essa criança!

Considerando ainda o desenvolvimento da criança abrigada, a mesma educadora menciona o caso de uma menina, que foi supostamente diagnosticada como hiperativa e que traz marcas profundas de rejeição:

... Eu tenho uma criança aqui, eu já chorei muito por causa dessa criança, é a que mais me dá trabalho. Essa criança é hiperativa, ela tem todos os defeitos de caráter que se possa imaginar, só que não são solidificados, são aquelas pluminhas que vão voando do caráter? Se você não remover, aquilo vai se solidificar e vai ser um indivíduo completamente torto. E continua, ela já teve uma adoção rejeitada, e sabe por que ela foi rejeitada? Porque era uma família muita bem de 
situação, pegou uma criança de abrigo, com uma idade acima dos três ou quatro anos, a criança ficou por conta de empregados, ela desobedeceu a todos, ela quase enlouqueceu a todos. A mãe simplesmente não teve pulso... e devolveu a criança. Vocês imaginam como é que ela está arrombada por dentro?

\section{Discussão}

Compreender e explicar os fatores que fazem parte do universo da criança abrigada, a partir de vários olhares representados pelos gestores, funcionários, que lidam diretamente com crianças em situação de risco foi 0 objetivo perseguido por este empenho de pesquisa que, apesar de suas modestas proporções, parece lançar alguma luz sobre os aspectos que envolvem a institucionalização de crianças pequenas. Assim, qual a concepção de criança que os gestores, funcionários e mães sociais têm das crianças que se encontram sob sua guarda e cuidados? Preliminarmente, chama atenção o modo como que, alguns representantes da instituição parecem entender 0 desenvolvimento da criança institucionalizada, o qual denota, em algumas de suas falas concepções quer ora se apresenta como essencialmente inatista, onde os fatores biológicos são determinantes nos processos de desenvolvimento e aprendizagem (Gesell \& cols., 1940). É interessante destacar a contribuição de Vigotskii (2001) ao enfatizar a importância da zona de desenvolvimento proximal, a qual deve ser ativada pelo mediador em suas interações com o mediado, de modo a propiciar a otimização de seu desenvolvimento. Nesse sentido, pressupostos teóricos que evidenciam a importância das interações no contexto institucional, se devidamente apropriados e trabalhados poderiam contribuir para uma saudável ruptura de préconceitos quanto ao modo da criança se desenvolver e aprender, mesmo estando acolhida em abrigos e tendo passado por experiências diversas, acompanhadas por sofrimentos marcantes.

De acordo com a ótica dos agentes institucionais, as maiores dificuldades apresentadas pelos abrigados são: carência afetiva; comportamentos agressivos, rebeldes, com os pares e com as mães sociais, dificultando 0 estabelecimento de limites; dificuldades escolares e problemas como a enurese noturna e experiências sexuais precoces. Spitz (1980) explica que a carência se refere à qualidade dos vínculos, determinantes para as conseqüências oriundas das privações afetivas que crianças pequenas são submetidas, entre elas a depressão, que passa por uma série de estágios, dependentes do tipo de privação sofrida.

A grande maioria das crianças participantes do estudo foram vítimas de maus tratos, o que pode levar a sentimentos de baixa auto-estima, comportamentos agressivos, dificuldades no estabelecimento de vínculos afetivos, isolamentos, sintomas psiquiátricos (Weber, Viezzer, Brandenburg \& Zocche, 2003) ou comportamentos rebeldes, vistos por Winnicott (1987), como necessidade de ser visto e reconhecido. Nesse sentido, acredita-se que comportamentos como a indisciplina não devem ser alijados do seu contexto, pois podem ser uma estratégia de sobrevivência no espaço institucional.
Uma situação muito freqüente é a referente à enurese noturna, cujo termo, segundo Soares, Moreira, Monteiro e Fonseca (2005), vem de enourein e significa urinar e isso acontece especificamente durante o período da noite. Geralmente, usa-se essa referência em crianças que já deveriam ter obtido tal controle e continuam a perder urina de forma involuntária. É um problema que merece atenção, pois parece estar associada a estados emocionais, como baixa-estima devido à separação entre os pais, internato, entre outros. Além disso, segundo as autoras, as crianças podem sofrer violências físicas e emocionais por serem interpretadas como rebeldes e preguiçosas quando urinam na cama, agravando mais seu estado emocional, levá-las ao estresse diante da eminência de serem ridicularizadas, à baixa-estima e ao isolamento.

Outro aspecto constantemente mencionado durante as entrevistas referiu-se à adultificação da sexualidade das crianças. Muitas intervenções realizadas pelos representantes da instituição ocorrem na tentativa de diminuir a incidência de experimentações sexuais entre elas, como não deixá-las irem para o quarto em grupos, utilizarem preceitos religiosos, entre outros. De acordo com algumas mães sociais, não é raro verificar relatos de crianças que experimentaram vivências sexuais precoces e com suspeitas de penetração hetero e homossexual em pré-adolescentes e, em alguns casos, com crianças pequenas. Freud (1969) mostrou no final do século XIX e início do século $X X$, que a sexualidade se iniciava na infância e como tal aspecto se apresenta de modo evidentemente exagerado nas crianças, sugere-se que sejam empreendidas investigações mais aprofundadas, em contextos de abrigo.

Com relação aos vínculos das crianças com suas famílias de origem, destaca-se o modo como as famílias das crianças abrigadas são concebidas no contexto institucional. Termos tais como: tratarem-se de pessoas inúteis, difíceis de confiar, desinteressadas, acomodadas são freqüentes nos discursos da equipe. Vale apontar que, via de regra, não há trabalhos efetivos junto às famílias, conforme evidenciaram Azôr e Vectore (2008).

Diante da ruptura freqüente do vínculo entre as mães sociais e crianças, tanto pela rotatividade, quanto pela adoção ou mesmo pela volta da criança à sua família de origem, uma questão intrigante é: até que ponto, o abrigo contribui no trabalho relativo aos desligamentos? É interessante constatar que, no que tange a importância da constituição dos vínculos no contexto do abrigo, observada pela ênfase dada pelo gestor acerca dos afetos propiciadores de segurança, que devem ser dirigidos às crianças, na sua valorização e preservação, há uma aparente incoerência, devido ao receio de que o apego demasiado pode comprometer outros procedimentos inerentes ao abrigamento (adoção, retorno à família de origem, entre outros).

A questão acima mencionada pode ser constatada no abrigo estudado, por exemplo, nas práticas rotineiras envolvendo mudanças de crianças de uma casa para outra, acarretando conseqüentemente, mudanças de mãe social, o que implica num processo contínuo de adaptações e readaptações das crianças e mães envolvidas. Em muitos casos, as mães sociais eram reconhecidas pelas crianças como verdadeiras mães, sendo tais rupturas acompanhadas por sofrimentos intensos, sentimentos de abandono e ressentimentos entre as partes. 
Além disso, há uma alta rotatividade de funcionários na instituição, em oito meses, sete saíram, desses, dois desistiram e cinco foram demitidos. Acredita-se que tal situação deva ser investigada, pois impõe novas rupturas nos vínculos estabelecidos junto às crianças e barreiras para a construção de um ambiente que se deseja ser seguro, em termos de possibilidade de tal vinculação. Em acréscimo, pode ser indicativa da dificuldade dos profissionais, em realmente cumprirem seu papel de educadores, sem o uso da agressão, como se depreende da fala a seguir ${ }^{3}$ :

...Ela deu uma surrinha de uma mãe, não é uma coisa de agressão... uma coisinha para realmente disciplinar. Então ela não vai ser punida, assim... se ficar assim entre mães porque se chegar ao conhecimento da autoridade, a lei às vezes é um pouco dura nesse sentido. (Itálico nosso)...Eu sou contra a violência, mas como a própria bíblia fala... "Fustigue a criança com uma vara e nem por isso ela morrerá, tu fustigarás com a vara e limpará sua honra".

Weber e cols. (2003) acentuam que, a associação de educação com punição, é responsável por situações de maus-tratos cometidos contra crianças, sendo necessário ser repensada por educadores ou responsáveis pela proteção de crianças, de modo a possibilitar uma maior capacitação dos profissionais para atuarem em contextos infantis. Por outro lado, um estudo de Faria, Salgueiro, Trigo e Alberto (2008) realizado com adolescentes portuguesas institucionalizadas em abrigo, mostra que as mesmas consideram importantes normas, regras e castigos "para o seu desenvolvimento e crescimento pessoal, pois através destes, adquirem valores fundamentais como segurança, estabilidade, organização, permanência e competências para a vida futura".

É importante salientar que, no estudo empreendido, não foi possível identificar uma uniformidade entre as perspectivas dos entrevistados acerca dos aspectos investigados; cada um possui, por exemplo, uma concepção de educação e uma ação diferenciada diante dos fatos vivenciados, indo desde a necessidade de castigos físicos até a negação dos mesmos. Nesse sentido, vale apontar a própria questão da inserção dos vínculos no contexto do abrigo, que se alterna entre a valorização até a negação de sua importância, uma vez que a permanência da criança deve ser temporária. Assim, talvez fossem interessante programas de formação e capacitação de profissionais atuantes em tais instituições, que propiciassem o aflorar de tais diversidades, de modo a possibilitar a construção de uma concepção mais homogênea e integradora da constituição humana entre os envolvidos.

Vale destacar que a formação profissional das mães sociais, responsáveis diretas no trato com as crianças, não é considerada como critério na admissão de um trabalho tão delicado, representado pelo lidar com as várias faces do abandono. Das mães sociais entrevistadas, apenas uma tem formação superior completa, duas terminaram o antigo magistério, três não possuem formação acadêmica, as outras duas, uma é cabeleireira e a outra é técnica em enfermagem. Conforme pode ser observado, o cuidado

\footnotetext{
${ }^{3}$ Devido aos procedimentos exigidos pelo Comitê de Ética, relativos à identificação dos informantes, não é possível mencionar a autoria de tal excerto.
}

com a formação não é priorizado, parecendo ser substituído por critérios como gostar de crianças, confirmando os estudos de Vectore (2005).

Além das experiências dolorosas vivenciadas antes da institucionalização, a criança abrigada parece dispor de um espaço restrito para manifestar os seus desejos e necessidades, de se fazer ouvida e compreendida, sujeitando-se continuamente às rotinas rígidas da instituição, às normas do judiciário, enfim, constituindo-se dia-a-dia num "sujeito sujeitado". Assim, é imprescindível dar voz à criança, de modo que possa se expressar, por meio da ampla variedade de linguagens, conforme identifica o famoso educador italiano Loris Malaguzzi (citado por Edwards, Gandini \& Forman, 1995). Segundo o autor, há "Cem Linguagens" disponíveis para as crianças e passíveis de torná-las sujeitos sociais com plenos direitos. Nesse aspecto, vale apontar que, há uma tendência mundial, nos estudos com crianças, em admitir a sua potencialidade e a sua possibilidade de expressão de suas particularidades e necessidades, conforme mostra Formosinho (2008). Desse modo, estudos que permitam ouvir a criança abrigada são bem-vindos e necessários.

\section{Considerações Finais}

Conhecer o intrincado universo da criança abrigada foi um dos propósitos deste estudo, engendrado por uma busca de vários olhares dos atores sociais envolvidos no processo de institucionalização infantil, olhares estes, que foram representados pelos gestores e funcionários que lidam dia-a-dia com $\mathrm{o}$ abandono e as dificuldades a ele inerentes.

Difícil não sofrer com o sofrimento das crianças. As dificuldades referem-se ao contato com as várias dimensões obscuras que o abandono traz e neste estudo, foi possível também identificar o abandono dentro da instituição, por meio das medidas tomadas para evitar a promoção do apego, como pode ser visto, no episódio da redistribuição das crianças para outras mães sociais, sem qualquer explicação e preparação prévias. Em relação a esse aspecto, acredita-se que seria de extrema relevância ter o profissional da psicologia, devidamente formado para o atendimento junto a tais contextos, inserido ou disponível para um trabalho contínuo na instituição, contribuindo com os seus saberes na composição de uma equipe multiprofissional.

As perspectivas de estudos no abrigo parecem inesgotáveis, a começar pelas famílias que tem seus filhos sob a guarda da justiça, a maioria passando por situações de miséria absoluta, vivendo em ambientes insalubres, mesclados de drogas, álcool e diversos tipos de privações. É incômodo saber que, o abrigo com característica de ser provisório, passa a constituir, na única possibilidade de um grande número de crianças, quando a adoção não se efetiva.

Adentrar e imergir no cotidiano da instituição mostrounos que os estudos acerca dessa temática estão longe de se esgotar, tamanha a complexidade que envolve a rede de relações inseridas nesse contexto. Assim, situações que envolvem o histórico das crianças, políticas públicas de apoio à família de origem, o abandono das crianças por famílias aparentemente desinteressadas, a institucionalização, relações que devem ser preservadas frente à importância dos vínculos afetivos, se existe 
incoerência ou parcialidade nas decisões de suspensão das visitas, a importância da formação de pessoal para trabalhar com as crianças, as rupturas dos vínculos no interior da instituição, a forma como tem sido trabalhado o processo de adoção, que permite a devolução da criança, com alegações de 'mau comportamento', as atitudes frente às relações construídas no espaço institucional, as atitudes com relação as dificuldades enfrentadas seja no desenvolvimento ou na aprendizagem dos abrigados, e mais uma gama de situações implícitas no cotidiano da instituição merecem pesquisas contínuas que possam originar políticas efetivas e eficientes de proteção à infância, assegurando, acima de tudo, a dignidade da criança frente à liberdade de exercer sua própria voz, geralmente abafada pela massificação do contexto.

\section{Referências}

Azôr, A. M. G. C. C. V., \& Vectore, C. (2008). Abrigar/desabrigar: conhecendo o papel das famílias nesse processo. Estudos de Psicologia, 25(1), 77-89.

Azôr, A. M. G. C. C. V. (2005). Abrigar... desabrigar: conhecendo o papel das famílias no processo de institucionalização/desinstitucionalização de abrigados. Dissertação de Mestrado em Psicologia Aplicada, Universidade Federal de Uberlândia, Uberlândia, Minas Gerais.

Cecconello, A., \& Koller, S. (2000). Competência social e empatia: Um estudo sobre resiliência com criança em situação de pobreza. Estudos de Psicologia, 5(1), 71-97.

Dorian, M. (2003). Repensando a perspectiva institucional e a intervenção em abrigos para crianças e adolescentes. Psicologia Ciência e Profissão, 21(3), 70-75.

Edwards, C., Gandini, L., \& Forman, G. (1995). I cento linguaggi dei bambini. Bologna, Itália: Edizione Junior.

Estatuto da Criança e do Adolescente (1990). Diário Oficial da União. Lei $n^{\circ} 8.069$ de 13 de julho de 1990. Brasília, D.F., Palácio do Planalto.

Faria, S. M. A. M., Salgueiro, A. G. B., Trigo, M. L. M. T. R., \& Alberto, I. M. M. (2008). As narrativas de adolescentes institucionalizadas: Percepções em torno das vivências de institucionalização. Em Anais do $1^{\circ}$ Congresso Internacional de Estudos da Criança, 2008, Portugal. Braga: Instituto de Estudos da Criança.

Formosinho, J. O. (Org.). (2008). A Escola vista pelas Crianças. Porto: Porto.

Freitas, M. (1997). História Social da infância no Brasil. São Paulo: Cortez.

Freud, S. (1969). A sexualidade infantil. Em Obras Completas: três ensaios sobre a sexualidade (Vol. VII, pp. 163-217). Rio de Janeiro: Imago.

Fundo das Nações Unidas para a Infância - UNICEF (2008). Relatório da situação mundial da infância 2007 Caderno Brasil.
[On-line]. Recuperado: 11 ago. 2008. Disponível: http://www.unicef.org.br/.

Gesell, A., Halverson, H. M., Thompson, H., Ilg, F. L, Costner, B. M., \& Amatruda, C. S. (1940). The First five years of life: A guide to the study of the preschool child. New York: Harper \& Row.

Instituto de Pesquisa Econômica Aplicada/Conselho Nacional dos Direitos da Criança e do Adolescente (2003). O Direito à convivência familiar e comunitária. Os abrigos para crianças e adolescentes no Brasil. Brasília: IPEA.

Maia, J. M. D., \& Williams, L. C. A. (2005). Fatores de risco e fatores de proteção ao desenvolvimento infantil: uma revisão da área. Temas em Psicologia, 13(2), 91-103.

Marcílio, M. L. (1997). A roda dos expostos e a criança abandonada na história do Brasil: 1726-1950. Em M. Freitas (Ed.), História Social da infância no Brasil (pp. 51-76). São Paulo. Cortez.

Panúncio, M. (2004). Infância Vitimizada e Vitimada: As implicações da violência para o desenvolvimento infantil e para a educação. Dissertação de Mestrado, Universidade de Uberaba, Uberaba, Minas Gerais.

Passeti, E. (1996). O menor no Brasil republicano. Em M. D. Priore (Org.), História da criança no Brasil (pp. 146-175). São Paulo: Contexto.

Silva, M. H. D. (2004). Crianças e jovens a cargo de instituições: Riscos reversíveis/irreversíveis. Em M. H. D. Silva, A. C. Fonseca, L. Alcoforado, M. M. Vilar \& C. M. Vieira (Eds.), Crianças e jovens em risco: Da investigação à intervenção (pp. 83-113). Coimbra: Almedina.

Silva, M., \& Lacharité, C. (2003). Resiliência: Concepções, fatores associados e problemas relativos à construção do conhecimento na área. Recuperado: 13 out. 2006. Disponível: http://sites.ffclrp.usp.br/paidéia/artigos/26/02.htm.

Soares, A., Moreira, M., Monteiro, L., \& Fonseca, E. (2005). A enurese em crianças e seus significados para suas famílias: abordagem qualitativa sobre uma intervenção profissional em saúde. Revista Brasileira de Saúde Materno Infantil, 5(3), 301-311.

Spitz, R. A. (1980). O Primeiro Ano de Vida da Criança. São Paulo: Martins Fontes.

Vectore, C. (2005). Estratégias mediacionais: possibilidades de inserção do psicólogo escolar / educacional em abrigos. Em A. M. Martinèz (Org.), Psicologia escolar e compromisso social (pp. 155175). Campinas, SP: Alínea.

Vicente, C. M. (2006). Abrigos: desafios e perspectivas. Acesso: 13 set. 2006. Disponível: www.cefit.org/trabtemas/abandono1.htm.

Vigotskii, L., Luria, A., \& Leontiev, A. (2001). Linguagem, desenvolvimento e aprendizagem. São Paulo: Ícone.

Weber, L. N., Viezzer, A. P., Brandenburg, O. J., \& Zocche, C. R. (2003). Famílias que maltratam: uma tentativa de socialização pela violência. Psico-USF, 7(2), 163-173.

Winnicott, D. W. (1987). Privação e delinqüência. São Paulo: Martins Fontes. 
Recebido em: 17/08/2008

Revisado em: 05/01/2009

Aprovado em: 08/01/2009

\section{Sobre os autores}

Cíntia Carvalho, Mestre em Psicologia Aplicada pelo Instituto de Psicologia da Universidade Federal de Uberlândia - MG Celia Vectore (vectore@ufu.br) Professora Associada 2, junto ao Instituto de Psicologia da Universidade Federal de Uberlândia - MG

Nota das autoras

Trabalho derivado da dissertação de Cíntia Carvalho, com o mesmo nome. 
